\title{
Clinical Trial Site Management Communication Material
}

National Cancer Institute

\section{Source}

National Cancer Institute. Clinical Trial Site Management Communication Material. NCI

Thesaurus. Code C115602.

A collection of communications, agreements, significant discussions, and/or relevant information related to clinical trial site management. 